Research Article

\title{
Association of FOSL1 copy number alteration and triple negative breast tumors
}

Leandro Tamião Rodrigues Serino ${ }^{1}$, Tayana Schultz Jucoski ${ }^{1}$, Stephanie Bath de Morais ${ }^{1}$, Cíntia Callegari Coêlho Fernandes ${ }^{1}$, Rubens Silveira de Lima $^{2}$, Cícero Andrade Urban², Luciane Regina Cavalli ${ }^{3}$, Iglenir João Cavalli $^{1}$ and Enilze Maria de Souza Fonseca Ribeiro ${ }^{1}$ (iD

${ }^{1}$ Laboratory of Human Cytogenetics and Oncogenetics, Departmentamento de Genética, Universidade Federal do Paraná, Curitiba, PR, Brazil.

${ }^{2}$ Breast Unit, Hospital Nossa Senhora das Graças, Curitiba, PR, Brazil

${ }^{3}$ Department of Oncology, Lombardi Comprehensive Cancer Center, Georgetown University, Washington, D.C., U.S.A.

\begin{abstract}
Copy number alterations (CNAs) are a frequent feature in human breast cancer, and one of the hallmarks of genomic instability. The FOSL1, GSTP1 and CCND1 genes are located at 11q13, a cytoband commonly affected by CNA in breast cancer, with relevant function in progression and invasion. Our main goal was to analyze CNAs of these genes and determine their association with breast cancer subtypes. Seventy-three cases of invasive breast tumors [52 Luminal, 7 HER2+ and 14 triple negative (TNBC) subtypes] were analyzed by TaqMan assays. CNAs were observed for all genes, with gains more frequently observed. Gains of the FOSL 1 gene were observed in $71 \%$ of the cases. This gene was the only one with a statistically significant difference $(p<0.001)$ among tumor subtypes, with increased copy number in TNBC compared to luminal and HER2+. No significant association of CNA and clinical and histopathological parameters from the patients was observed. Additional studies in larger breast cancer patient cohorts based on more refined molecular subtypes are necessary to confirm the observed association of FOSL1 gain with aggressive breast tumors phenotypes.
\end{abstract}

Keywords: Triple negative breast cancer, TNBC, DNA copy number alterations, CNA.

Received: September 01, 2017; Accepted June 13, 2018

\section{Introduction}

Breast cancer is the cancer with the highest incidence among women worldwide. The incidence varies widely around the world, with rates from 19.3 new cases per 100,000 women in East Africa to 89.7 per 100,000 in Western Europe (Globocan, 2016). In Brazil, the estimate is of nearly 56 new cases per 100,000 women (INCA, 2016); about $50 \%$ of the cases and $58 \%$ of the deaths occur in lowand middle-income countries due to advanced stage diagnosis (WHO, 2016).

Based on gene expression arrays, breast cancers are classified into five major molecular subtypes: luminal A and B, basal, HER2 (Human Epidermal Growth Factor Receptor 2) positive and normal-like (Perou et al., 2000; Sorlie et al., 2003); other defined subtypes have also been identified in these studies including the interferon-rich, claudin low, and molecular apocrine (Farmer et al., 2005; Prat et al., 2010; Eroles et al., 2012). These subtypes differ not only with regard to their pattern of gene expression and clinical features,

Send correspondence to Enilze M. S. F. Ribeiro. Genetics Department, Federal University of Parana, 81531-980, Curitiba, PR, Brazil. E-mail: enilzeribeiro@gmail.com. but also in the response to treatment and clinical outcome (Sorlie et al., 2003; Rouzier et al., 2005; Sotiriou and Pusztai, 2009; Weigelt et al., 2010; Martin et al., 2011).

Although gene expression profiling has greatly contributed for the determination of breast cancer subtypes and its associated differential prognosis, at present, this defined "intrinsic" molecular classification is not routinely used in clinical practice to classify the patient's breast tumor subtypes. Among the main reasons are the prohibitive costs of the equipment and reagents of the expression assays, and the lack of adequate technical personnel to conduct the complex informatics data analysis. A simplified clinicopathological classification, that defines subtypes based on the immunohistochemical analysis of ER, PR, HER2 receptors status and Ki-67 labeling index is instead adopted (Goldhirsch et al., 2011, 2013). The breast cancer subtypes, Luminal A and B, HER2+, and triple negative breast cancer (TNBC), defined by this classification, are similar to the five main intrinsic subtypes, and represent a convenient approximation that can be performed in considerably less expensive and less complexes assays.

Copy number alterations (CNAs) are changes in gene copy number that have arisen in somatic tissue and are a 
frequent feature in human breast cancer, and one of the hallmarks of genomic instability (Hanahan and Weinberg, $2000,2011)$. We recently investigated the copy number status of the genes FOSL1, GSTP1 and CCND1 in primary breast tumors with lymph node metastasis (Callegari et al., 2016). These genes are mapped at 11q13 region, a cytoband commonly affected by CNA in breast cancer, and present relevant function in breast cancer progression and invasion (Santos et al., 2008). The FOSL1 gene belongs to the FOS family, which regulates several processes such as cell proliferation, differentiation, metastasis, angiogenesis, apoptosis and stimulating genes associated with hypoxia (Wisdom and Verma, 1993; Shaulian and Karin, 2002; Milde-Langosh, 2005; Kharman-Biz et al., 2013). The Glutathione S-transferase pi 1 (GSTP1) gene belongs to the family of Pi class GSTs and is involved in cellular detoxification processes. High expression of GSTP1 was observed in cell lines treated with chemotherapy drugs, pointing to the potential involvement of this protein in tumor resistance to chemotherapeutic treatments (Batist et al., 1986; Hayes and Pulford, 1995; Huang et al., 2003). The CCND1 gene encodes the Cyclin D1 protein, that plays an important role in cell cycle regulation, controlling the transition from the G1 to S phases (Massague, 2004). CCND1 copy gain occurs in about $15-20 \%$ of breast tumors and its mRNA and protein was found overexpressed in approximately $50 \%$ of breast cancers, suggesting that other mechanisms than CNAs are involved in its expression regulation (Buckley et al., 1993; Gillett et al., 1994; Maia et al., 2015).

In this study, we evaluated whether the CNAs present in these genes were associated with the IHC defined breast cancer major subtypes and with patients' clinical and histopathological parameters.

\section{Material and Methods}

\section{Sample Characterization}

Seventy-three samples from primary breast carcinomas classified as invasive ductal carcinoma (IDC) were collected during primary surgery at the Hospital Nossa Senhora das Graças (HNSG), Curitiba, state of Paraná, South of Brazil, prior to any cancer treatment. The samples were collected with the patients' written informed consent, and under approval of the local Ethical Committee in Human Research. The samples were immediately immersed in a transport medium, de-codified and sent without patients' identifiers to the Laboratory of Human Cytogenetics and Oncogenetics (Genetics Department, Federal University of Parana).

Clinical and histopathological information regarding the age of patients, histological grade of tumors, and presence or absence of metastasis in axillaries lymph nodes, as well as immunohistochemical markers were retrieved from the pathological and medical reports (de-codified) and are summarized in Table 1. Samples were classified into subtypes Luminal A, Luminal B, HER2+, and triple negative breast cancer (TNBC) according to the status of hormone receptors ER and PR, Ki-67, and HER2 proteins, based on the St Gallen International Expert Consensus (Goldhirsch et al., 2013). Based on ER and PR positivity (when $\geq 1 \%$ of tumor cells were immunoreactive according to Hammond et al. (2010), samples are classified in Luminal. The proliferation marker protein Ki-67 discriminate Luminal A $(\leq 14 \%)$ and B (high), as well as the PR marker absent or low (indicating Luminal B with any Ki-67). Luminal B can also be divided in HER2 positive or negative (defined according to Wolff et al., 2014). When positive, just the ER positivity is necessary to define Luminal B, with any Ki-67 and any PR result. Samples without expression of ER and PR are classified as HER2 positive (non-luminal) and TNBC (ER, PR and HER2 negative). In our sample, we noticed a great number of patients (see Suplementary Material Table S1) without the Ki-67 data, and even though these patients were classified individually, in the statistical analysis the group was described as "Luminal", without the subdivision A e B. TNM classification was based on AJCC $8^{\text {th }}$ Edition (Amin et al., 2016).

Table 1 - Clinical and histopathological information.

\begin{tabular}{|c|c|c|c|c|c|}
\hline & Sample size & Age (yrs) & Grade $(\%)$ & LN metastasis $(\%)$ & Lymphovascular invasion \\
\hline $\mathrm{ER}^{+}, \mathrm{PR}^{+}, \mathrm{HER}^{-/+}$ & $\mathrm{N}=54$ & $59 \pm 14.55$ & Grade I (12.2) & Pos (52) & Present (47.8) \\
\hline \multirow[t]{2}{*}{ (Luminal) } & & & Grade II (61.2) & Neg (48) & Absent (52.2) \\
\hline & & & Grade III (26.5) & & \\
\hline $\mathrm{ER}^{-}, \mathrm{PR}^{-}, \mathrm{HER} 2^{+}$ & $\mathrm{N}=8$ & $63 \pm 14.66$ & Grade I (0) & Pos $(87.5)$ & Present (16.7) \\
\hline \multirow[t]{2}{*}{$\left(\mathrm{HER}^{+}{ }^{+}\right)$} & & & Grade II (12.5) & & \\
\hline & & & Grade III (87.5) & $\operatorname{Neg}(12.5)$ & Absent (83.3) \\
\hline $\mathrm{ER}^{-}, \mathrm{PR}^{-}, \mathrm{HER} 2^{-}$ & $\mathrm{N}=14$ & $51 \pm 10.17$ & Grade I (0) & Pos $(42.8)$ & Present (64.3) \\
\hline \multirow[t]{2}{*}{$(\mathrm{TNBC})$} & & & Grade II (57.1) & $\operatorname{Neg}(57.2)$ & Absent (35.7) \\
\hline & & & Grade III (42.8) & & \\
\hline
\end{tabular}

ER: Estrogen receptor; PR: Progesterone receptor; HER2: Human Epidermal Growth Factor Receptor 2; LN: lymph node; Pos: lymph node positive; Neg: lymph node negative; TNBC: triple negative breast cancer. 


\section{Copy number analysis}

After confirmation of cancer diagnosis, the DNA was isolated by standard phenol-chloroform methods in snap frozen tissue samples. A pool of peripheral blood DNA from women with no cancer was used as control.

TaqMan ${ }^{\circledR}$ Copy Number Assays (Life Technologie) was used for the copy number analysis, using specific gene assays for FOSL1, GSTP1 and CCDN1, as we previously described (Callegari et al., 2016). RNASE $P$ was used as a reference gene. The samples, including control DNA, were analyzed in triplicate using 96 well plates in the Viia 7 (Applied Biosystem) equipment. PCR conditions included an initial denaturation step at $95{ }^{\circ} \mathrm{C}$ for $10 \mathrm{~min}$, followed by 40 cycles at $95{ }^{\circ} \mathrm{C}$ for $15 \mathrm{~s}$ and $60{ }^{\circ} \mathrm{C}$ for $1 \mathrm{~min}$. Data analyses were performed using the Copy Caller software (Life Technologies). Samples that presented a CT value $>33$ cycles and a $\mathrm{z}$-score [\#GTEQ\#] 2.65 were not considered. The number of copies of the DNA of each sample (DNA test) was calculated in comparison with the control DNA; gains were considered for gene copy number of 2.51 or above, loss for 1.49 or below; and normal between 1.50 and 2.50 .

\section{Statistical Analysis}

The data were analyzed using the Kruskal-Wallis, Dunn, Student's $t$, chi-square tests, and linear regression, with a statistical significance value set at $p<0.05$.

\section{Results}

Seventy-three female patients, mean age $57.7 \pm 13.7$ (median 58 years old), diagnosed with primary breast cancer were studied. Clinico-pathological information is summarized in Table 1 and fully described in Table S1.

Copy number alterations (CNAs) were observed for all the genes analyzed in this study. Gains of copy number were the most frequent CNAs observed, most frequently for the FOSL1 gene (71\% of the cases), followed by CCNDI (27\% of the cases) and GSTP1 (25\% of the cases). Losses were observed in a lower frequency as follows: $6 \%$ for FOSL1, 3\% for GSTP1 and 10\% for CCND1. For the GSTP1 and CCND1 genes there was no statistically signifi- cant difference among the CNAs observed and their distribution according to the IHC (Luminal, TNBC and HER2) defined tumor subtypes $\left(\chi_{2}^{2}=2.44 ; \mathrm{P}>0,20 \mathrm{p}=0.1130\right.$ and $\chi_{2}^{2}=0.43 ; \mathrm{P}>0.80 p=0.3092$ and $\chi_{2}^{2}=5.79 ; \mathrm{P}>0.05$, respectively) (Figure 1). For the FOSL1 gene, the $\chi^{2}$ value is at the significance limit.

Related to FOSL1 gene and IHC subtypes, CNAs were presented in an average of $2.98 \pm 1.80$ of the Luminal, $4.27 \pm 1.79$ of HER2, and $4.82 \pm 2.14$ of TNBC subtypes. These differences were tested by Fisher's test. The Bartlett's test showed that the variances were homogeneous $\left(\chi_{2}^{2}\right.$ (corr) $=0.64 ; \mathrm{P}>0.70$ ), and the $\mathrm{F}$-value was significant $(\mathrm{F}=6.08 ; \mathrm{P}<0.05)$. Using Turkey's test a significant difference was observed between the means of TNBC and Luminal subtypes $(\Delta=1.35<1.84)$. Linear regression test showed that CNAs in this gene were dependent of the tumor subtype $(b=0.094 \pm 0.27 ; p<0.001)$ (Figure 2).

We did not observe significant differences among the CNAs (normal vs. alterations) of the three genes analyzed and the patients' clinical and histopathological parameters: mean age of patients under or over 50 years old $\left(\chi_{1}^{2}=0.11 ; \mathrm{P}>0.70, \quad \chi^{2}{ }_{1}=0.28 ; \quad \mathrm{P}>0.50 \quad\right.$ and $\quad \chi_{1}^{2}=2.55$; $\mathrm{P}>0.10$ ), respectively for FOSL1, GTSP1 and CCND1, tumor grade (I + II vs. III, $\left(\chi_{{ }_{1}}^{2}=0.98 ; \mathrm{P}>0.30, \chi^{2}{ }_{1}=0.34\right.$; $\mathrm{P}>0.50$ and $\chi_{1}^{2}=0.03 ; \mathrm{P}>0.80$, respectively), and lymph node metastasis status $\left(\chi_{1}^{2}=1.90 ; \quad \mathrm{P}>0.10, \quad \chi_{1}{ }_{1}=0.58\right.$; $\mathrm{P}>0.30$, and $\chi_{1}^{2}=1.05 ; \mathrm{P}>0.30$, respectively).

In addition, we did not observe significant differences among the three subtypes of tumors (Luminal, HER2 and TNBC) and lymphovascular invasion $\left(\chi_{2}^{2}=2.84 ; \mathrm{P}>0.20\right)$ and presence of distant metastasis $\left(\chi_{2}^{2}=3.60 ; \mathrm{P}>0.10\right)$, but a significant difference was observed for grade I+II vs. III $\left(\chi_{2}^{2}=8.51 ; \mathrm{P}<0.05\right)$. The difference was mainly due to the value of the partial $\chi^{2}(6.87 / 8.51=81 \%)$ observed in the HER2 subtype and, probably, due to the low number of cases analyzed.

Finally, according to the data described in Table S1, 55 patients presented follow up information (41 classified as luminal, 4 HER2 and 10 TNBC). The mean of the clinical follow up time of the 41 luminal patients was $86.24 \pm$

\section{CCND1}

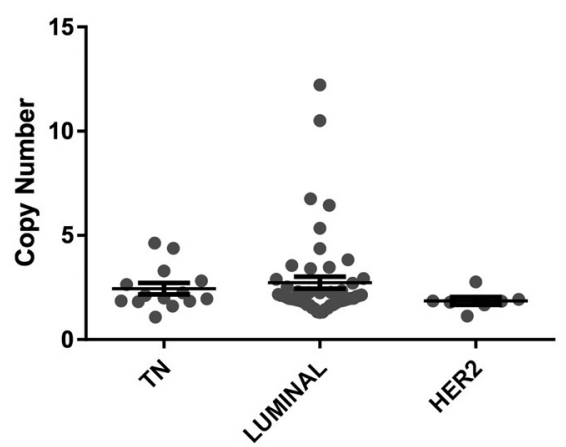

FOSL1

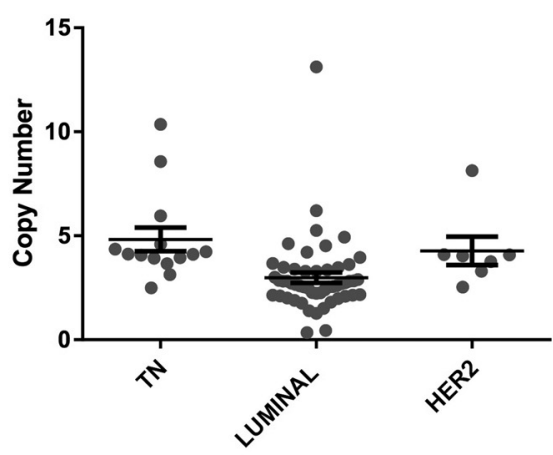

GSTP1

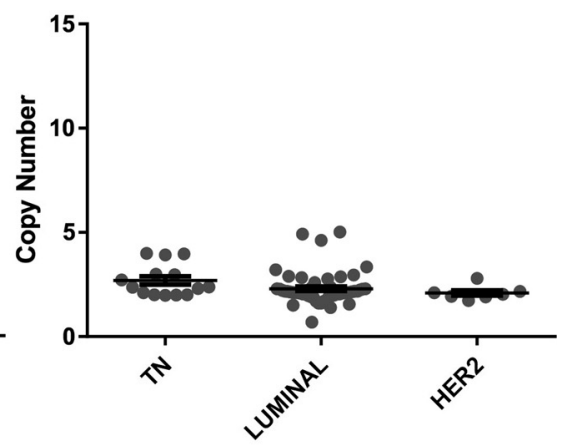

Figure 1 - Copy number alterations (CNAs) of the CCND1 FOSL1 and GSTP1genes according to the IHC defined breast tumor subtypes. 


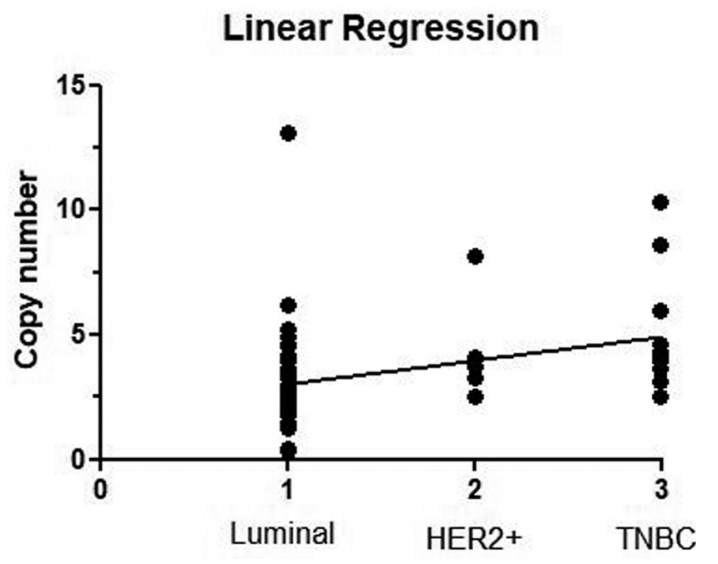

Figure 2 - Distribution of the copy number alterations (CNAs) of the FOSL1 gene and linear regression analysis according to the IHC defined breast cancer subtypes. Abbreviation: TNBC - Triple Negative Breast Cancer.

45.32 months, of the 4 HER2 patients was $41.25 \pm 33.17$ months and of the 10 TNBC patients was $62.7 \pm 38.6$ months. In each subtype, two patients died, respectively $5 \%, 50 \%$, and $20 \%$ in the luminal, HER 2 , and TNBC subtypes. As expected, the number of patient deaths was not equally distributed in the three subtypes of tumors $\left(\chi_{2}^{2}=\right.$ 8.6; $\mathrm{P}<0.05)$, but the difference was mainly due to the value of the partial $\chi^{2}(6.22 / 8.60=72 \%)$ observed in the HER2 subtype that presented a low number of the patients. The difference between the means of the clinical follow up time observed in the subtypes luminal and TNBC was not significant $(t=1.51 ; \mathrm{P}>0.10)$. Thirty-seven patients $(57 \%)$ were alive and with no evidence of disease (NED) and 18 (33\%) presented some event (EV), like death, local relapse, or distant metastasis (Table S1). We did not observe a differential distribution of CNAs among the patients in the two groups (54 and 26 CNAs respectively for NED and EV), but we could notice that the FOSL1 gene showed the highest frequency of CNAs (26 and 17 respectively for NED and EV), with predominance in the two more aggressive subtypes, HER2 and TNBC (Table S1).

\section{Discussion}

In this study, we evaluated the copy number of FOSL1, GSTP1, CCND1 in different subtypes of breast carcinomas, classified according to the status of hormone receptors, ER and PR, KI-67, and HER2 protein. It is important to address that the classification based on immunohistochemistry (IHC) is similar but not identical to intrinsic subtypes (using genetic array testing) and represent a convenient approximation. For example, the IHC subtype TNBC overlaps $80 \%$ with the intrinsic "basal-like" subtype, but includes some special histological types such as medullary and adenoid cystic carcinoma (Goldhirsch et al., 2011).

The genes were selected based on their critical roles in breast cancer, as well as on our previous study on pri- mary breast cancer, showing the preferentially involvement of the $11 \mathrm{q} 13$ region, where these genes are mapped, in copy number alterations (CNAs) (Santos et al., 2008).

Here were observed CNAs for all the three genes evaluated, with gains being the predominant change (71\% for FOSL1, 27\% for CCND1, and $25 \%$ for GSTP1). Considering the physical proximity of these genes in 11q13, they could simultaneously be affected by copy number gain/amplification or loss/deletion. In our samples, we observed that gains, losses, or no alterations of these genes were not equally distributed $\left(\chi^{2}=40.05, \mathrm{P}<0.001\right)$ mainly due to the FOSL1 result, but corroborating this hypotheses.

The FOSL1 gene was observed with the highest frequency of CNAs in our study and the only one with a significant difference among subtypes, more specifically between TNBC and Luminal subtypes. In addition, among patients with follow up, FOSL1 showed the highest CNAs frequency in the two more aggressive subtypes, HER2 and TNBC. To our knowledge although there are several reports on FOSL1 gene expression changes, there are no reports in relation to its copy number. Since the report of Kustikova et al. (1998), the correlation of FOSL1 expression and mesenchymal characteristics of epithelial tumors is well accepted. Overexpression in epithelioid carcinoma cells greatly influences cell morphology, motility, and invasiveness. Belguise et al. (2005) induced the overexpression of FOSL1 in the MCF-7 cell line (ER+ and less aggressive) and the subexpression in the MDA-MB-231 (TN phenotype and more aggressive) showing that the modulation of FOSL1 expression directly affected cell proliferation, invasiveness, and motility of these cells in vitro. In the same direction, Kharman-Biz et al. (2013) and Zhao et al. (2014) independently observed that FOSL1 expression was higher in TNBC compared to luminal tumors. These and other studies indicate overall that tumor cells with high metastatic capabilities present higher expression of FOSL1 (Zajchowski et al., 2001; Zhao et al., 2014). Although we did not perform an expression analysis of this gene, based on our findings we suggest that CNAs of FOSL1 can be one of the mechanisms that lead to the reported overexpression of this gene in aggressive breast tumors, such as TNBC. Data from our research group (Callegari et al., 2016), however, did not find a specific correlation between FOSL1 copy number and mRNA expression in breast tumors in general, although only a small number of samples was analyzed $(\mathrm{n}=31)$.

The GSTP1 gene was observed with normal copies in $72 \%$ of the breast tumor cases evaluated in this study and gain in $23 \%$ of the cases. No significant difference for this gene was observed in relation to its copy number and tumor subtypes and/or clinical-pathological parameters. The described alteration of the GSTP1 enzyme in breast tumors can be due to the presence of polymorphisms in this gene, such as the Ile105Val polymorphism, where the homozygous Ile has been shown to confer increase in its enzymatic activity (Ünlü et al., 2008; Khabaz, 2014). Data from our 
group described in Torresan et al. (2008) studying the same polymorphism in Euro-descendant patients in southern Brazil, found a positive association between the Val allele and the risk of breast cancer when combined with polymorphisms in the CYP genes. However, others found no association between the Ile105Val polymorphism and breast cancer risk (Ünlü et al., 2008; Khabaz, 2014).

The CCND1 gene was observed with a copy number gain in $26 \%$ of our cases. This data is consistent with other studies that found amplification of this gene in approximately $15-20 \%$ of breast tumors (Gillett et al., 1994; Holm et al., 2012; Burandt et al., 2014). However, we did not find any association of CNAs in this gene with the breast cancer subtypes and clinical and histopathological parameters from the patients.

In conclusion, we showed in this study that the FOSL1, GSTP1, and CCND1 genes present gains of copy number in invasive breast tumors. Regression analysis showed that CNAs of the FOSL1 gene were significantly dependent of the tumor subtype TNBC when compared to the luminal tumors, suggesting its association with aggressive breast tumor phenotypes. Additional studies in larger breast cancer patient cohorts and classified based on the more refined molecular subtypes, are necessary to confirm these findings.

\section{Acknowledgments}

This study was partially funded by $\mathrm{CNPq} /$ Fundação Araucária (Edital PRONEX 2012). Scholarships to LTRS, TSJ and CCCF were provided by the Coordenação de Aperfeiçoamento de Pessoal de Nível Superior - Brasil (CAPES) - Finance Code 001.

\section{Conflict of interest}

The authors declare that there is no conflict of interest that could be perceived as prejudicial to the impartiality of the reported research.

\section{Author contributions}

LTRS designed the study, conducted the experiments, analyzed the data. TSJ analyzed the data. SBM conducted the experiments. CCCF designed the study, analyzed the data and wrote the manuscript. RSL and CAU provided the samples and clinical data, LRC analyzed the data and wrote the manuscript. IJC analyzed the data, and wrote the manuscript, EMSFR conceived the study, supervised the experiments, analyzed the data and wrote the manuscript. All authors read and approved the final version.

\section{References}

Amin MB, Edge S, Greene F, Byrd DR, Brookland RK, Washington MK, Gershenwald JE, Compton CC, Hess KR, Sullican DC et al. (2016) AJCC Cancer Staging Manual. 8th edition. Springer, New York, 507 p.
Batist G, Tulpule A, Sinh BK, Katki AG, Myers CE and Cowan KH (1986) Over-expression of a novel anionic glutathione transferase in multi-drug resistant human breast cancer cells. J Biol Chem 261:15544-15549.

Belguise K, Kersual N, Galtier F and Chalbos D (2005) FRA-1 expression level regulates proliferation and invasiveness of breast cancer cells. Oncogene 24:1434-1444.

Buckley MF, Sweeney KJ, Hamilton JA, Sini RL, Manning DL, Nicholson RI, DeFazio A, Watts CK, Musgrove EA and Sutherland RL (1993) Expression and amplification of cyclin genes in human breast cancer. Oncogene 8:2127-2133.

Burandt E, Grünert M, Lebeau A, Choschzick M, Quaas A, Jänicke F, Müller V, Scholz U, Bokemeyer C, Petersen C et al. (2014) Cyclin D1 gene amplification is highly homogeneous in breast cancer. Breast Cancer 23:111-119.

Callegari CC, Cavalli IJ, Lima RS, Jucoski TS, Torresan C, Urban CA, Kuroda F, Anselmi KF, Cavalli LR and Ribeiro EM (2016) Copy number and expression analysis of FOSL1, GSTP1, NTSR1, FADD and CCND1 genes in primary breast tumors with axillary lymph node metastasis. Cancer Genet 209:331-339.

Eroles P, Bosch A, Pérez-Fidalgo JA and Lluch A (2012) Molecular biology in breast cancer: Intrinsic subtypes and signaling pathways. Cancer Treat Rev 38:698-707.

Farmer P, Bonnefoi H, Becette V, Tubiana-Hulin M, Fumoleau P, Larsimont D, Macgrogan G, Bergh J, Cameron D, Goldstein $\mathrm{D}$ et al. (2005) Identification of molecular apocrine breast tumours by microarray analysis. Oncogene 24:4660-4671.

Gillett C, Fantl V, Smith R, Fisher C, Bartek J, Dickson C, Barnes D and Peters G (1994) Amplification and overexpression of Cyclin D1 in breast cancer detected by immunohistochemical staining. Cancer Res 54:1812-1817.

Goldhirsch A, Wood WC, Coates AS, Gelber RD, Thürlimann B and Senn HJ (2011) Strategies for subtypes - dealing with the diversity of breast cancer: Highlights of the St. Gallen International Expert Consensus on the Primary Therapy of Early Breast Cancer 2011. Med Oncol 22:1736-1747.

Goldhirsch A, Winer EP, Coates AS, Gelber RD, Piccart-Gebhart M, Thürlimann B and Senn HJ (2013) Personalizing the treatment of women with early breast cancer: Highlights of the St Gallen International Expert Consensus on the Primary Therapy of Early Breast Cancer 2013. Annals Oncol 24:2206-2223.

Hammond ME, Hayes DF, Dowsett M, Allred DC, Hagerty KL, Badve S, Fitzgibbons PL, Francis G, Goldstein NS, Hayes M et al. (2010) American Society of Clinical Oncology/College of American Pathologists guideline recommendations for immunohistochemical testing of estrogen and progesterone receptors in breast cancer. J Clin Oncol 28:2784-2795.

HanahanD and Weinberg RA (2000) The hallmarks of cancer. Cell 100:57-70.

Hanahan D and Weinberg RA (2011) Hallmarks of cancer: The next generation. Cell 144:646-674.

Hayes JD and Pulford DJ (1995) The Glutathione S-Transferase supergene family: Regulation of GST and the contribution of the isoenzyme to cancer chemoprotection and drug resistance. Crit Rev Biochem Mol 30:445-600.

Holm K, Staaf J, Jönsson G, Vallon-Christersson J, Gunnarsson H, Arason A, Magnusson L, Barkardottir RB, Hegardt C, Ringnér M et al. (2012) Characterisation of amplification patterns and target genes at chromosome 11q13 in CCND1 
amplified sporadic and familial breast tumours. Breast Cancer Res Treat 133:583-594.

Huang J, Tan P, Thiyagarajan J and Bay B (2003) Prognostic significance of Glutathione S-transferase pi in invasive breast cancer. Mod Pathol 16:558-565.

Khabaz MN (2014) Polymorphism of the Glutathione S-Transferase P1 gene (GST-Pi) in breast carcinoma. Pol J Pathol. 65:141-146.

Kharman-Biz A, Gao H, Ghiasvand R, Zhao C, Zendehdel K and Dahlman-Wright K (2013) Expression of activator protein-1 (AP-1) family members in breast cancer. BMC Cancer $13: 441$

Kustikova O, Kramerov D, Grigorian M, Berezin V, Bock E, Lukanidin E and Tulchinsky E (1998) Fra-1 induces morphological transformation and increases in vitro invasiveness and motility of epithelioid adenocarcinoma cells. Mol Cell Biol 18:12:7095-7105.

Maia LBL, Breginski FSC, Cavalcanti TCS, Souza RL, Roxo VM and Ribeiro EM (2015) No difference in CCND1 gene expression between breast cancer patients with and without lymph node metastasis in a Southern Brazilian sample. Clin Exp Med 16:593-598.

Martin M, Romero A, Cheang MC, García-Asenjo JAL, GarcíaSaenz JA, Oliva B, Román JM, He X, Casado A, de la Torre $\mathrm{J}$ et al. (2011) Genomic predictors of response to doxorubicin versus docetaxel in primary breast cancer. Breast Cancer Res Treat 128:127-136.

Massague J (2004) G1 cell-cycle control cancer. Nature 432:298306.

Milde-Langosch K (2005) The Fos family of transcription factors and their role in tumourigenesis. Eur $\mathrm{J}$ Cancer 41:2449-2461.

Perou CM, Sorlie T, Eisen MB, van de Rijn M, Jeffrey SS, Rees CA, Pollack JR, Ross DT, Johnsen H, Akslen LA et al. (2000) Molecular portraits of human breast tumours. Nature 406:747-752.

Prat A, Parker JS, Karginova O, Fan C, Livasy C, Herschkowitz JI, He X and Perou CM (2010) Phenotypic and molecular characterization of the claudin-low intrinsic subtype of breast cancer. Breast Cancer Res 68:12:1-18.

Rouzier R, Perou CM, Symmans WF, Ibrahim N, Cristofanilli M, Anderson K, Hess KR, Stec J, Ayers M, Wagner P et al. (2005) Breast cancer molecular subtypes respond differently to preoperative chemotherapy. Clin Cancer Res 11:56785685.

Santos SC, Cavalli IJ, Ribeiro EM, Urban CA, Lima RS, BleggiTorres LF, Rone JD, Haddad BR and Cavalli LR (2008) Patterns of DNA copy number changes in sentinel lymph node breast cancer metastases. Cytogenet Genome Res 122:1621.

Shaulian E and Karin M (2002) AP-1 as regulator of cell life and death. Nat Cell Biol 4:131-136.

Sorlie T, Tibshirani R, Parker J, Hastie T, Marron JS, Nobel A, Deng S, Johnsen H, Pesich R, Geisler S et al. (2003) Repeated observation of breast tumor subtypes in independent gene expression data sets. Proc Natl Acad Sci USA 100:8418-8423.
Sotiriou C and Pusztai L (2009) Gene-expression signatures in breast cancer. N Engl J Med 360:790-800.

Torresan C, Oliveira MMC, Torrezan GT, Oliveira SF, Abuázar CS, Losi-Guembarovski R, Lima RS, Urban CA, Cavalli IJ and Ribeiro EM (2008) Genetic polymorphism in oestrogen metabolic pathway and breast cancer: A positive association with combined CYP/GST genotypes. Clin Exp Med $8: 65-71$.

Ünlü A, Ates NA, Tamer L and Ates C (2008) Relation of glutathione S-transferase T1, M1 and P1 genotypes and breast cancer risk. Cell Biochem Funct 26:643-647.

Weigelt B, Baehner FL and Reis-Filho JS (2010) The contribution of gene expression profiling to breast cancer classification, prognostication and prediction: A retrospective of the last decade. J Pathol 220:263-280.

Wisdom R and Verma IM (1993) Transformation by Fos proteins requires C-terminal transactivation domain. Mol Cell Biol 13:7429-7438.

Wolff AC, Hammond ME, Hicks DG, Dowsett M, McShane LM, Allison KH, Allred DC, Bartlett JM, Bilous M, Fitzgibbons $\mathrm{P}$ et al. (2014) Recommendations for human epidermal growth factor receptor 2 testing in breast cancer: American Society of Clinical Oncology/College of American Pathologists clinical practice guideline update. Arch Pathol Lab Med 138:241-256.

Zajchowski DA, Bartholdi MF, Gong Y, Webster L, Liu HL, Munishkin A, Beauheim C, Harvey S, Ethier SP and Johnson PH (2001) Identification of gene expression profiles that predict the aggressive behavior of breast cancer cells. Cancer Res 61:5168-5178.

Zhao C, Qiao Y, Jonsson P, Wang J, Xu L, Rouhi P, Sinha I, Cao Y, Williams C and Dahlman-Wright K (2014) Genomewide profiling of AP-1-regulated transcription provides insights into the invasiveness of triple-negative breast cancer. Cancer Res 74:14.

\section{Internet resources}

Globocan (2016) Estimated cancer incidence, mortality, and prevalence worldwide in 2012, http://globocan.iarc.fr/Pages/fact_sheets_cancer.aspx. (accessed 20 July 2016)

INCA (2016) Instituto Nacional do Câncer. Ministério da Saúde. Secretaria de Atenção à Saúde. Coordenação de Prevenção e Vigilância. Estimativas 2014: Incidências de Câncer no Brasil, http://www.inca.gov.br. (accessed 20 July 2016)

WHO (2016) World Health Organization. WHO Cancer Control Programme, http:// www.who.int/cancer/en/. (accessed 20 July 2016)

\section{Supplementary material}

The following online material is available for this article: Table S1 - Clinico-pathological information, classification, follow up and DNA copy number of 73 patients.

Associate Editor: Anamaria Aranha Camargo

License information: This is an open-access article distributed under the terms of the Creative Commons Attribution License (type CC-BY), which permits unrestricted use, distribution and reproduction in any medium, provided the original article is properly cited. 